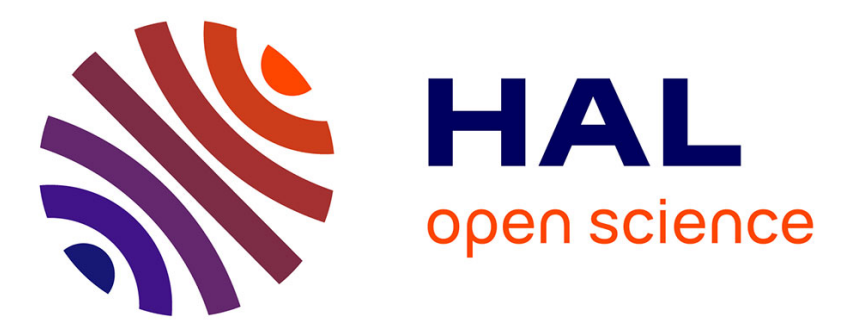

\title{
Thermal diffusivity measurement by I.R. microscopy : application to opaque polymeric samples
}

\author{
J. Guitonny, G. Pandey, A. Boccara, D. Fournier
}

\section{To cite this version:}

J. Guitonny, G. Pandey, A. Boccara, D. Fournier. Thermal diffusivity measurement by I.R. microscopy: application to opaque polymeric samples. Journal de Physique IV Proceedings, 1994, 04 (C7), pp.C7-307-C7-309. 10.1051/jp4:1994773 . jpa-00253302

\section{HAL Id: jpa-00253302 https://hal.science/jpa-00253302}

Submitted on 1 Jan 1994

HAL is a multi-disciplinary open access archive for the deposit and dissemination of scientific research documents, whether they are published or not. The documents may come from teaching and research institutions in France or abroad, or from public or private research centers.
L'archive ouverte pluridisciplinaire HAL, est destinée au dépôt et à la diffusion de documents scientifiques de niveau recherche, publiés ou non, émanant des établissements d'enseignement et de recherche français ou étrangers, des laboratoires publics ou privés. 


\title{
Thermal diffusivity measurement by I.R. microscopy: application to opaque polymeric samples
}

\author{
J. Guitonny*, G.C. Pandey, A.C. Boccara** and D. Fournier* \\ Research Center, Indian Petrochemical Corpn. Ltd., Baroda 391346, India \\ * Lab. d'Instrumentation, UPMC, UPR A0005 du CNRS, ESPCI, 10 rue Vauquelin, 75005 Paris, France \\ ** Lab. Optique Physique, UPR A0005 du CNRS, ESPCI, 10 rue Vauquelin, 75005 Paris, France
}

\begin{abstract}
In this paper, we have used an IR imaging system coupled with an IR detector to explore the periodically heated field in order to measure thermal diffusivity. Results on low diffusivity materials such as polymers are shown.
\end{abstract}

\section{INTRODUCTION}

Measuring thermal diffusivity of polymer using mirage detection by probing the temperature field in air or gas is rather difficult for low diffusivity materials due to the domination of heat transfert processes in the surrounding gas [1] [2]. In this paper, we propose to use an IR microscope coupled to an IR detector in order to explore the heated area and to deduce the thermal diffusivity at a submilimeter scale. The same kind of experimental setup has been used few years ago by Rief and al. [3] on carbon fiber reinforced plastic (CFRP) in order to show the correlation between the thermal wave data and the Young's modulus fiber. When there is a offset between the detector spot and the laser spot, it is possible to measure the phase angle of the thermal wave and they have shown that the phase of thermal signal is a function of the fibre volume fraction.

In our case after describing the setup, we shall show experimental results obtained on opaque polymeres.

\section{EXPERIMENTAL SETUP}

Figure 1 shows our experimental setup. The temperature field is induced by local heating of the opaque sample surface due to an intensity modulated argon laser beam focused with a $7 \mathrm{~cm}$ focal length lens. The modulation frequencies used were 5 and $12 \mathrm{~Hz}$. The heated area is probed by an $\mathrm{HgCdTe} \mathrm{IR}$ detector $(250 \times 250 \mu \mathrm{m})$ coupled with an IR imaging system. We have used a catadioptric microscope objective (magnification 10 or 36) followed by a $\mathrm{ZnSe}$ lens (focal length $5 \mathrm{~cm}$ ). The typical size of the probed sample surface is $70 \times 70 \mu \mathrm{m}$. Because of this large collection angle of the infrared flux the sensitivity of the setup is rather good. 


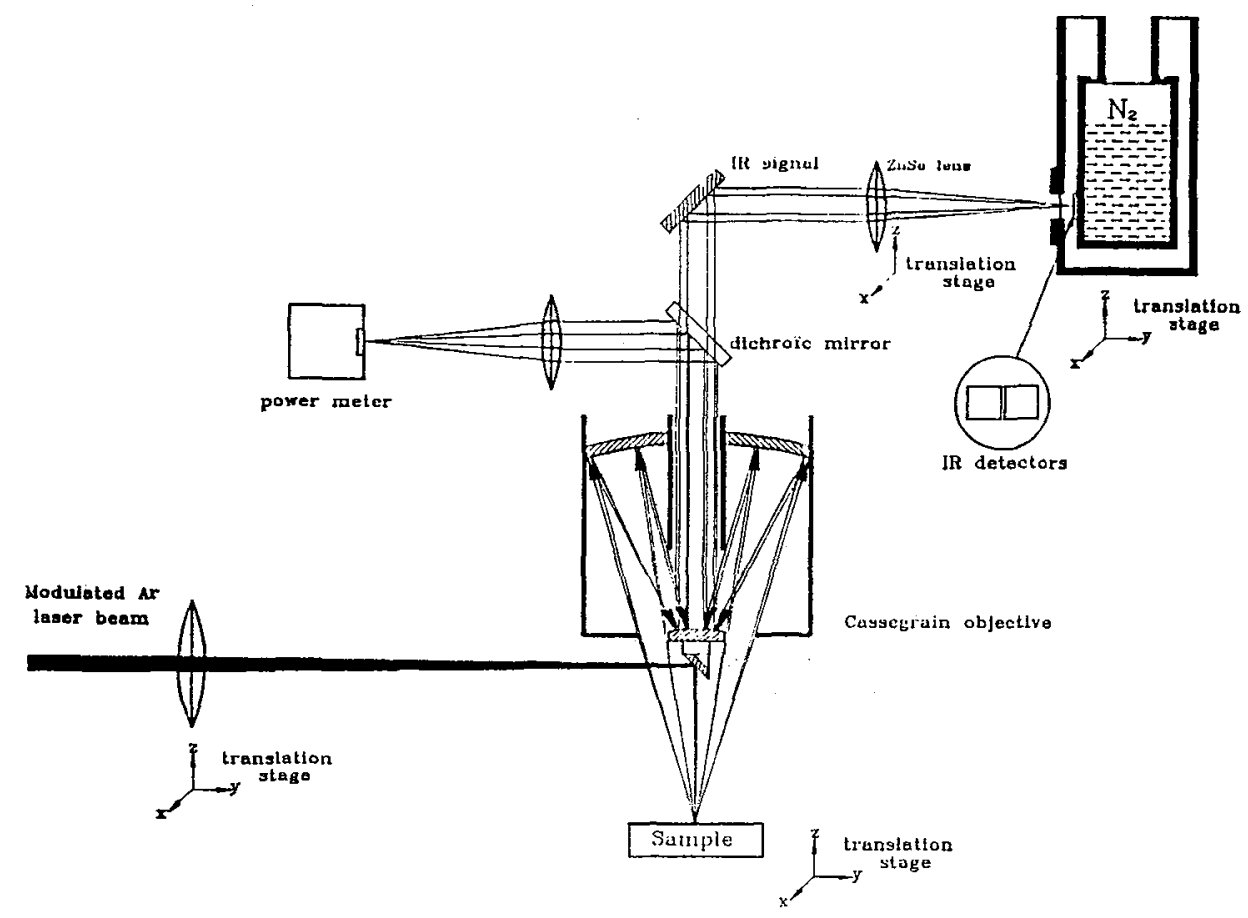

Figure 1 : Experimental setup

An image of the periodically heated field can be recorded by scanning the detector position with two micropositionners. We found that this setup is relatively insensitive to topographic and optical irregularities because we achieve the measurement of the temperature field with the phase of the signal.

\section{RESULTS}

To illustrate the ability of our setup to achieve the thermal diffusivity measurement of critical samples we have examined various kinds of opaque polymer samples such as carbon loaded plastic and carbon fibers embedded in a polymer plastic.

Figure 2 shows the phase of the signal recorded as a function of the heating spot image of the detector distance on our unprepared carbon loaded polymer matrix and we assume that the phase varies linearly with the ratio distance/ $\mu, \mu$ being the thermal diffusion length. So, the thermal diffusivity deduced from the slope of this recording is $2,7.10^{-3} \mathrm{~cm}^{2} / \mathrm{s}$.

Let us notice that this kind of experiment can also be achieved if the sample is not completely opaque in the IR. Indeed the small depth of field of the imaging system selects only a small volume close to the surface. Moreover a computer simulation of this detection shows that for such measurement wich probes the radial heating at the surface, the result is not affected by the presence of air.

Figure 3 shows the results obtained on an uncoated bundle on a carbon fibers; this sample is made up of several carbon fibers whose are closed, and the experiments are carried out moving the detector paralelle to the axis fiber. In this case the diffusivity obtained is $33,75 \mathrm{~cm}^{2} / \mathrm{s}$. As expected, the diffusivity perpendicular to the fibers is smaller $\left(6,45,10^{-3} \mathrm{~cm}^{2} / \mathrm{s}\right)$ because the discontinuities between the fibers. 


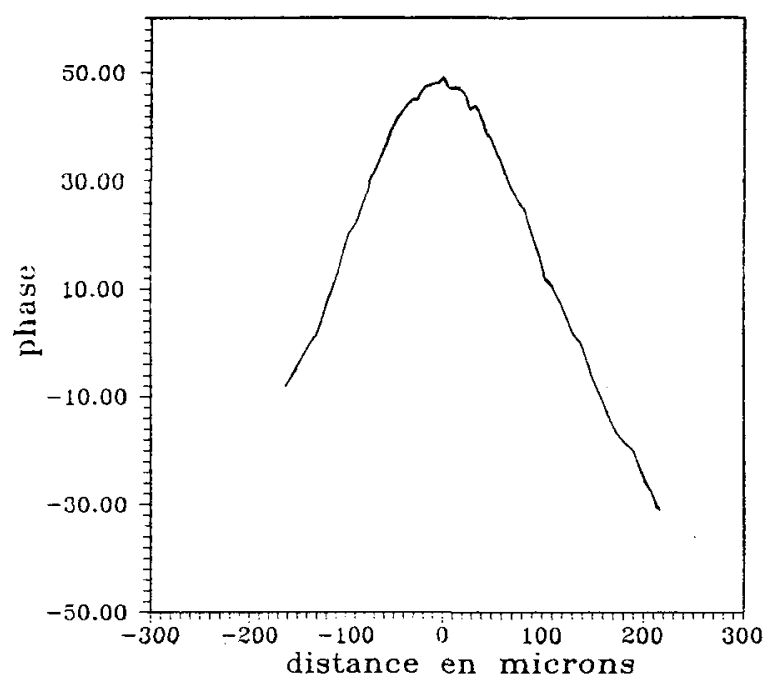

Figure 2 : unprepared carbon loaded polymer matrix

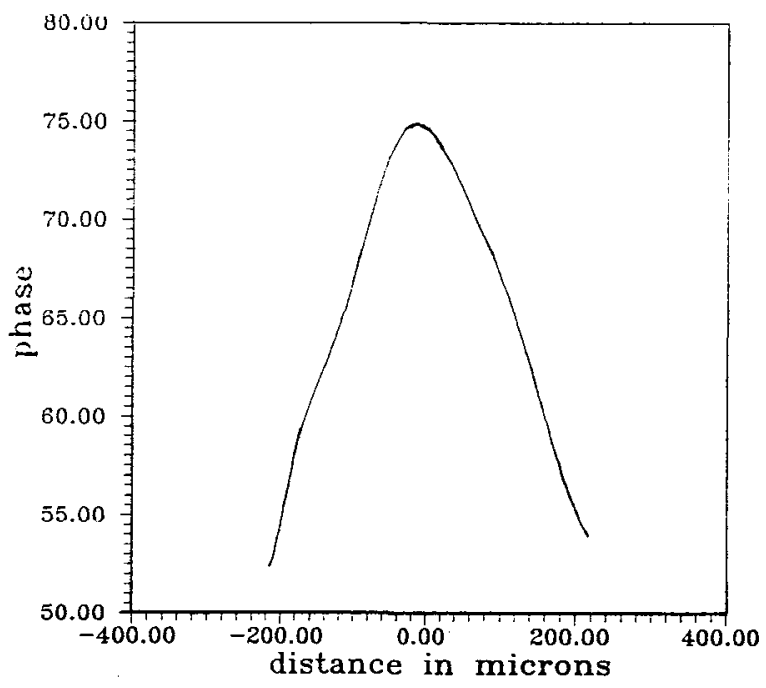

Figure 3 : uncoated bundle of carbon fibers

\section{CONCLUSION}

In conclusion, we have described a method which allows to measure the local diffusivity of post thermal diffusivity sample opaque at one wavelength (excitation) and opaque or slightly emitting at the $I R$ detector wavelength

[1] : B. Skagerberg, J. Jaarinen, Jukka Rantala, Rev. Sci. Instrum. 63 (8), August 1992, p. 3959-3965

[2] : P. K. Kuo and al., Can. J. Phys. 64, 1986, p. 1165-1167

[3] : B. Rief, G. Busse, P. Eyerer, Proceed. ICCMVI/ECCM2, Elsevier Applied Science Publisher London (1987) 